Sección Medicina

Prof, E. Cienfuegos.

Servicio Niños Mayores

Dr. J. Daneri.

Hospital M. Arrìrán.

\title{
OSTEOMIELITIS TRATADA Y MEJORADA CON SULFATIAZOL
}

Por los Dres. WALTER Galasso V. y SAMUel FINKELSTEIN $\mathbf{R}$.

E. C., de 9 años de edad. Es traido por persona extraña, que no proporciona antecedentes satisfactorios.

Enfermedad actual. - La persona que lo acompaña relaciona su enfermedad con una caida de caballo que el niño sufre cinco días atrás y que se traduce por fiebre, decaimiento y manifestaciones poliarticulares dolorosas.

Es hospitalizado en el Servicio de Medicina Interna y con el resultado del examen clínico practicado en la sala y el fundamento de los exámenes de laboratorio solicitados, si piensa en una infección reumática con insuficiencia mitral. La localización posterior de la sintomatología dolorosa y objetiva en la articulación del hombro derecho con mejoria completa de toda otra sintomatología articular, nos hacen solicitar una radiografía (N." 36509), cuyo informe dice "Aspecto borroso đe la metáfisis superior del húmero derecho sospechoso d'z osteomielitis en comienzo"."

Otros exámenes practicados dan los siguientes resultados: $R$. Wassermann y Reacción de Kahn negativas. Reacción de Mantoux 1 por 10,000, negativa. Radioscopia pulmonar notmal. Examen de orina normal. Sedimentación alta. Hemograma; leucocitosis con neutrofilia.

Es trasladado al Servicio de Cirugía con el diagnóstico de osteomielitis del tercio superior del lxúmeto derecho. 

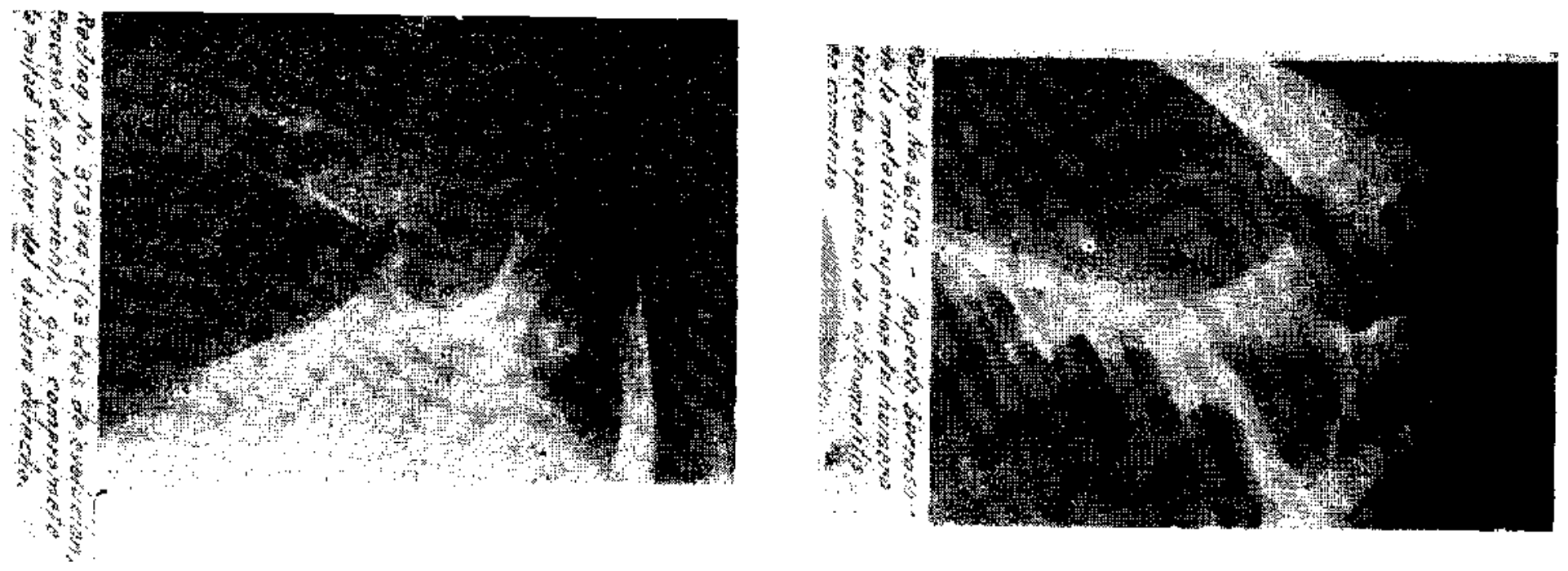


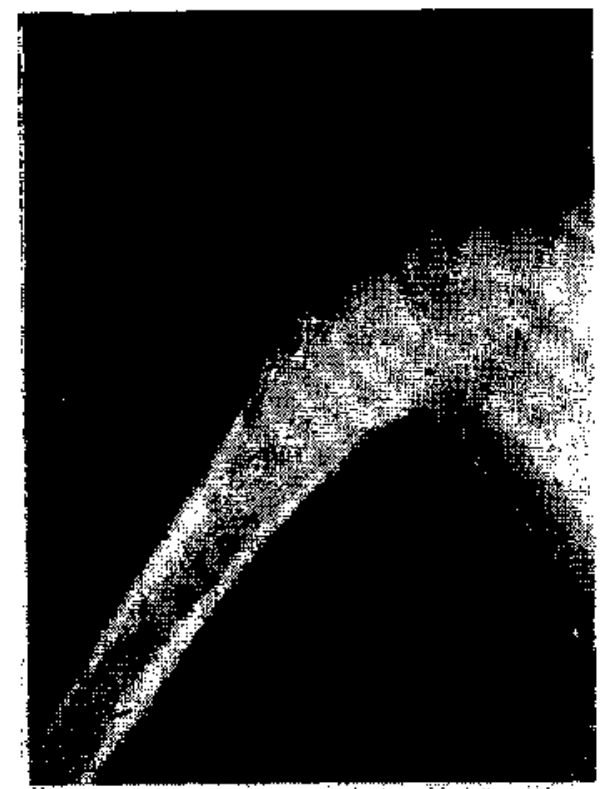

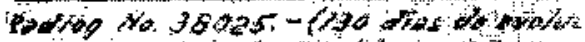

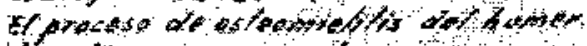

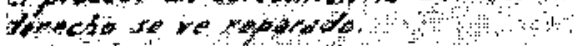

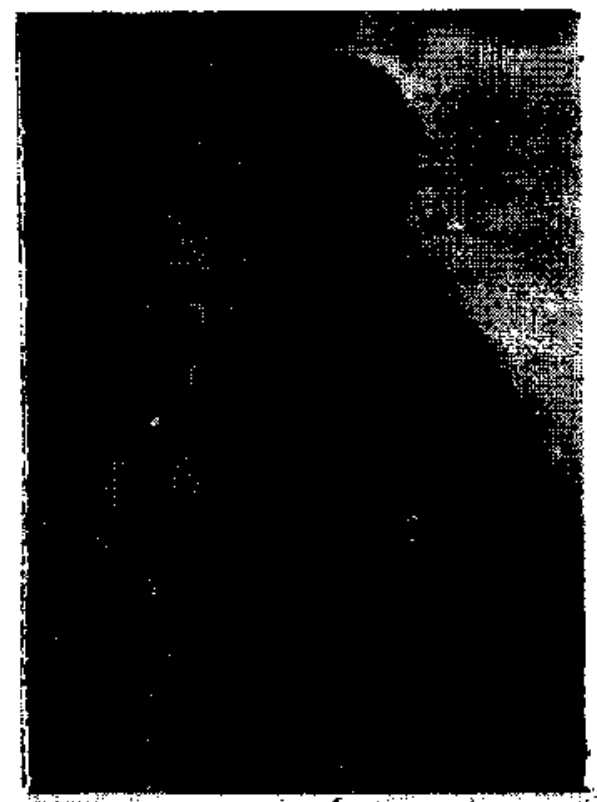

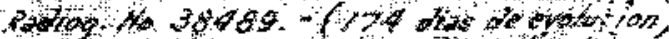

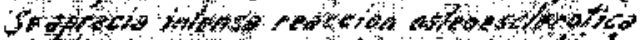

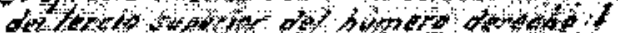

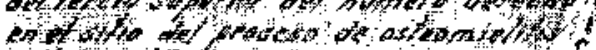

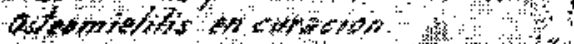


En el Servicio señalado permanece 43 días y en el curso de la evolución presenta un absceso del hombro derecho que es incindido y la secreción purulenta enviada al laboratorio. El examen denota la presencia del Stafillacoco Dorado. Es tratada con Sulfanilamida a la dosis de 0.15 por kilo peso, administrando una dosis total de 39 gts.

El enfermo es presentado a la reunión clínica semanal del Hospital y de su discusión se concluye: "Sepsis a Stafilococo Dorado que ha producido una poli-sinovitis que regresa completamente, una osteomielitis del húmero derecho en evolución y una probable lesión endocárdica que se traduce clínicamente en un soplo sistólico suave de la punta y que se deja én observación".

Es dado de alta del Servicio de Cirugía muy mejorado y con la reccmendación de concurrir a control al Policlinice.

El enfermito permanece 18 días en su casa y no cumple con la indicación de asistir all Políclinico.

Es hospitalizado en el Servicio de Medicina y al examen. se comprueba un grave compromiso del estado general, una reagudización de la osteomielitis que se traduce por intensos dolores e impotencia funcional absoluta de, la extremidad superior derecha y una glomérulo nefritis isquémica difusa aguda complicada de insuficiencia cardiaca.

La gravedad de la lesión de osteomielitis se aprecia en el informe de la radiografía N. 37344 "Proceso de osteomie"jtis que compromete la mitad superior del húmero derecho".

La insuficiencia cardíaca evolucionó favorablemente con el tratamiento respectivo en cinco días y la lesión renal sigue un carso benigno; las pruebas funcionales renales practicadas a los 72 dias son satisfactorias.

La lesión de osteomielitis es tratada con inmovilización y es scmetida a una cura intensa periódica y controlada de sulfatiazol con dosis que fluctúan en $0.30,0,20$ y 0.15 por kilo peso y que no produce ningún efecto tóxico.

Ya a los siete días de iniciada la cura sulfotiazólica, la sintomatología grave subjetiva y objetiva disminuye notablemente.

E1 control radiográfico (N. $\left.{ }^{\circ} 38025\right)$ efectuado a los 130. días de evolución desde la iniciación de la osteomielitis y consecutive a una cura en 70 días, de 182 grs. de sulfatia$\mathrm{zcl}$ informa: "El proceso de osteomielitis del húmero dere. cho se ve reparado".

E1 control radiográfico (N. 38489 ) verifícado a los 174 días de evolución y posterior a una cura total de 206 
gre. de sulfatiazol, informa: "Se aprecia intensa reacción osteocsclerótica del tercio superior del húmero derecho en el sitio del proceso de osteomielitis. Osteomielitis en curación".

El estudio clínico, el telediagrama y el electro-fonocardiograma efectuados por el Servicio de Cardiología del Hospital, coneluye que no hay lesión otgánica del corazón.

En resumen, una observación de una osteomielitis del húmerc derecho que es tratada con una dosis total de 206 grs. de sulfatiazol con una evolución hacia la mejoría controlada por los exámenes radiográficos recalcando que el período de tiempo transcurrido entre la radiografía N. ${ }^{\circ} 37344$ y la radiegrafía N.938025, es sólo de 70 días. 